\title{
Effect of Graphene on Microstructure and Mechanical Properties of $\mathrm{Si}_{3} \mathrm{~N}_{4} / \mathrm{SiC}$ Ceramics
}

\author{
Hailing Yang, ${ }^{1}$ Qinggang Li, ${ }^{1}, *$ Zhi Wang, ${ }^{2} \mathrm{Hao} \mathrm{Wu},{ }^{2}$ Yuying $\mathrm{Wu},{ }^{3}$ Pengkun $\mathrm{Hou}^{1}$ and Xin $\mathrm{Cheng}^{1}$
}

\begin{abstract}
Graphene with $0.3 \%$ content was added to enhance the fracture toughness of $\mathrm{Si}_{3} \mathrm{~N}_{4} / \mathrm{SiC}$ ceramics prepared by pressureless sintering. The microstructure, mechanical properties and toughening mechanism of ceramics were investigated. Results showed that the fracture strength significantly increased from 329.11 MPa to 443.19 MPa after adding graphene. The main toughening mechanism of ceramics was crack deflection since the existence of graphene platelets. The main phase compositions of samples were $\beta-\mathrm{Si}_{3} \mathrm{~N}_{4}$ with a high aspect ratio and SiC located in the grain boundary, and the SiC particles could avoid the excessive growth of $\beta-\mathrm{Si}_{3} \mathrm{~N}_{4}$ to reduce the strength.
\end{abstract}

Keywords: Silicon nitride $\left(\mathrm{Si}_{3} \mathrm{~N}_{4}\right)$; Silicon carbide ( $\left.\mathrm{SiC}\right)$; Graphene; Mechanical properties.

Received date: 11 January 2021; Accepted date: 1 February 2021.

Article type: Research article.

\section{Introduction}

Graphene, in recent years, has attracted considerable attention in the fields of physics, chemistry and materials due to its excellent properties. Graphene is a monolayer twodimensional structure assembled by carbon atoms via $\mathrm{sp}^{2}$ hybridized bonds, and it has high specific surface area, excellent mechanical and thermal properties. ${ }^{[1-4]}$ In addition, it also has distinctive electronic properties owing to the microscopic corrugations of surface. ${ }^{[1]}$ The fracture strength of single graphene sheets is $130 \mathrm{GPa}$, and the Young's modulus is $1 \mathrm{TPa}$, according to reports. ${ }^{[4,5]}$ Therefore, graphene is often used as the reinforced phase to improve the mechanical properties of materials such as polymers, ${ }^{[6,7]}$ metal matrix composites and ceramics. Khan et al.$^{[7]}$ reported that both the Young's modulus and the stress at 3\% strain increase exponentially with the mass fractions above $50 \mathrm{wt}$. \%. There are many of studies have reported that metal-based materials reinforced by graphene were successfully prepared. ${ }^{[4,8,9]}$ Tian $^{[4]}$ and $\mathrm{Li}$ et $a .^{[8]}$ reported that the mechanical properties

\footnotetext{
1 Shandong Provincial Key Laboratory of Preparation and Measurement of Building Materials, Jinan 250022, China.

${ }^{2}$ School of Material Science and Engineering, University of Jinan, Jinan 250022, China.

3 Key Laboratory for Liquid-Solid Structural Evolution and Processing of Materials, Ministry of Education, Shandong University, 17923 Jingshi Road, Jinan 250061, China.

*E-mail: mse_liqg@ujn.edu.cn (Q. Li)
}

including hardness, compressive, strength and yield strength are enhanced of aluminum matrix composites with the addition of low content graphene. It could be attributed to the homogeneous distribution of graphene in the matrix, the clean and strong interface between the Al matrix and graphene formed via metallurgical bonding.

Graphene is also widely used to toughen ceramic materials because the inherent drawbacks as brittleness of ceramics cannot be ignored. ${ }^{[10-15]} \mathrm{Kim}^{[10]}$ and Fan ${ }^{[11]}$ et al. studied that fracture toughness and hardness were improved simultaneously by adding graphene nanosheet for the $\mathrm{Al}_{2} \mathrm{O}_{3}$ ceramics, besides, the dielectric properties were also improved. A few reports with $\mathrm{Si}_{3} \mathrm{~N}_{4}$ have demonstrated that graphene platelets could significantly improve the mechanical properties. ${ }^{[12-15]}$ Based on microstructural observations of crack paths, connected matrix and protruding graphene were found, which proved that the toughening mechanisms were the crack deflection, crack bridging and pulling out of graphene. ${ }^{[10-17]}$ In addition, it was found that adding low-content graphene was beneficial to enhance the mechanical properties of composites (not only to ceramics) while the deterioration would be generated with the increase of content due to the agglomeration of graphene platelets. ${ }^{[4,8,9,15]}$ There are many of studies on pure ceramics strengthened by graphene, while multiphase ceramics are also inadequate. $\mathrm{Si}_{3} \mathrm{~N}_{4}$-based ceramics are widely used as structural components at temperatures because of their high strength, relative chemical stability and corrosion resistance, but the toughness still needs to be improved. ${ }^{[18-20]}$ The effect of $\mathrm{SiC}$ 

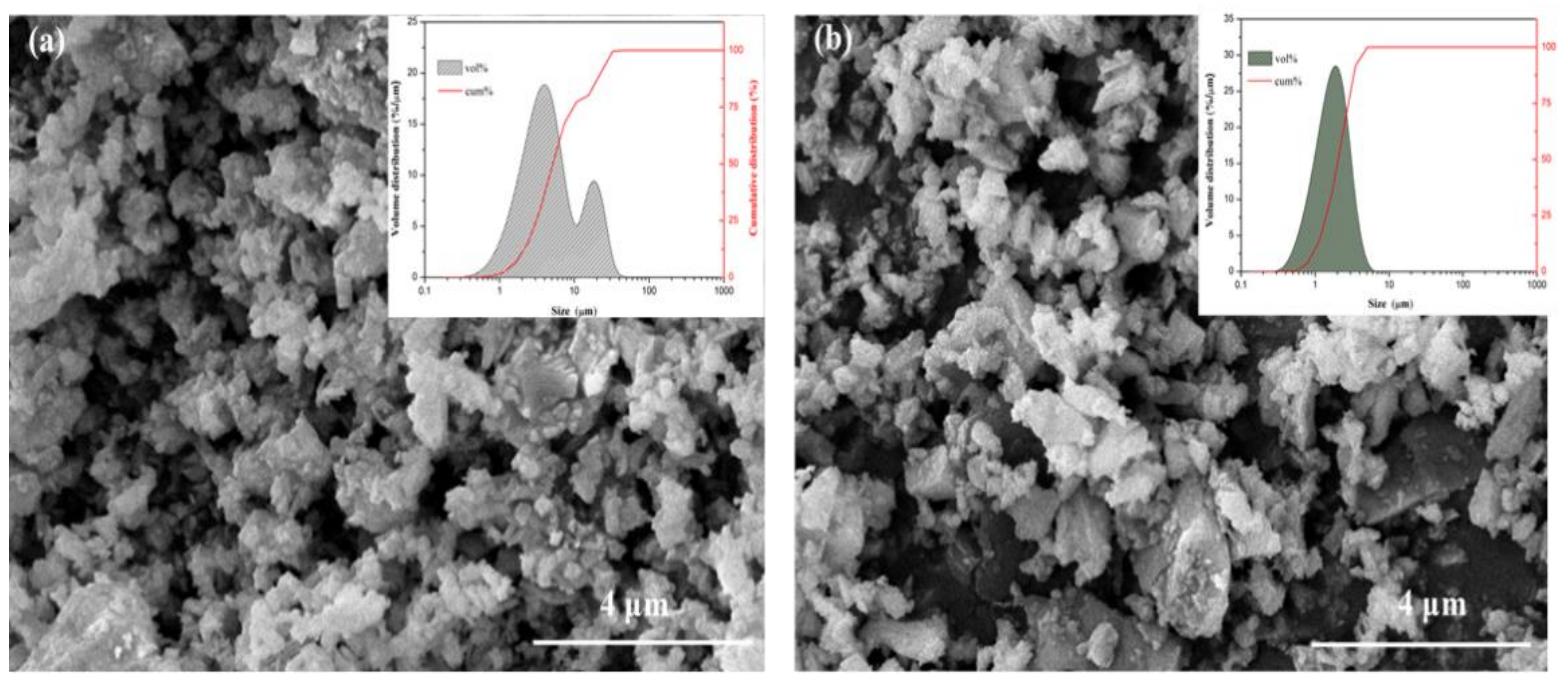

Fig. 1 SEM images of raw materials: (a) $\mathrm{Si}_{3} \mathrm{~N}_{4}$; (b) $\mathrm{SiC}$.

nanoparticles in $\mathrm{Si}_{3} \mathrm{~N}_{4} / \mathrm{SiC}$ composite ceramics are to pin grain boundaries, refine grains and inhibit propagation of cracks, ${ }^{[18,19,21]}$ and rod-like $\beta-\mathrm{Si}_{3} \mathrm{~N}_{4}$ strengthens ceramic by selfinterlocking. ${ }^{[2,15]}$ This paper purposes to improve toughness by adding graphene. Spark plasma sintering (SPS) is always used to prepare the composites due to its faster heating rates, shorter sintering times, low-pressure and high-quality method. ${ }^{[1,15,22]}$ However, the $\beta-\mathrm{Si}_{3} \mathrm{~N}_{4}$ grain growth will be eliminated because of lower temperature and shorter holding time. ${ }^{[20]}$

Thus, in this paper, in order to analyze the influence of graphene on the mechanical properties, $0.3 \%$ graphene was added to prepare the $\mathrm{Si}_{3} \mathrm{~N}_{4} / \mathrm{SiC}$ composite ceramic using cold isostatic pressing and pressure less sintering at high temperature. And investigated the strength mechanism of $\mathrm{Si}_{3} \mathrm{~N}_{4} / \mathrm{SiC}$ ceramic by analyzing the phase composition and microstructure.

\section{Materials and method}

\subsection{Sample Preparation}

$\mathrm{Si}_{3} \mathrm{~N}_{4}$ powders $(\alpha$-phase $92 \%, \beta$-phase $8 \%$, Shanghai STNano Technology Co., Ltd., Shanghai, China) and $\mathrm{SiC}$ powders (purity $>99.9 \%$, Shanghai ST-Nano Technology Co. Ltd., China) were used as starting powders, and the weight ratio of $\mathrm{Si}_{3} \mathrm{~N}_{4}$ and $\mathrm{SiC}$ is 95:5. As shown in Fig. 1, the average diameter of $\mathrm{Si}_{3} \mathrm{~N}_{4}$ was $5 \mu \mathrm{m}$ and the $\mathrm{SiC}$ was $2 \mu \mathrm{m}$, there were no obvious agglomeration for $\mathrm{Si}_{3} \mathrm{~N}_{4}$ (Fig. 1(a)) and $\mathrm{SiC}$ particles (Fig. 1 (b)), respectively. Graphene was added as additive, and two groups of samples were prepared with the content of $0 \%$ and $0.3 \%$ graphene, which were named SC and $\mathrm{SCC}$, respectively. The micrograph of graphene was shown in Fig. 2, the graphene was a two-dimensional material composed of a single layer of carbon atoms with a transparent folded surface. The common out-of-plane distortion of graphene, wrinkling (Fig. 2 (a) and (b)) and rippling (Fig. 2 (c)), could be observed.

The mixtures were ball-milled in ethanol for $12 \mathrm{~h}$, followed by drying for $15 \mathrm{~h}$ at $85^{\circ} \mathrm{C}$, and then sieving through 250 mesh. The microtopography of mixtures for SC and SCG as illustrated in Fig. 3, the $\mathrm{SiC}$ and $\mathrm{Si}_{3} \mathrm{~N}_{4}$ distributed evenly across the surface of graphene layers which was conducive to the formation of uniform body. Afterward, the green body was formed by the cold isostatic pressing method under $200 \mathrm{MPa}$ for $2 \mathrm{~min}$. Finally, under the nitrogen atmosphere, the composite ceramics were obtained by sintering at $1950{ }^{\circ} \mathrm{C}$ for $1.5 \mathrm{~h}$ without pressure.
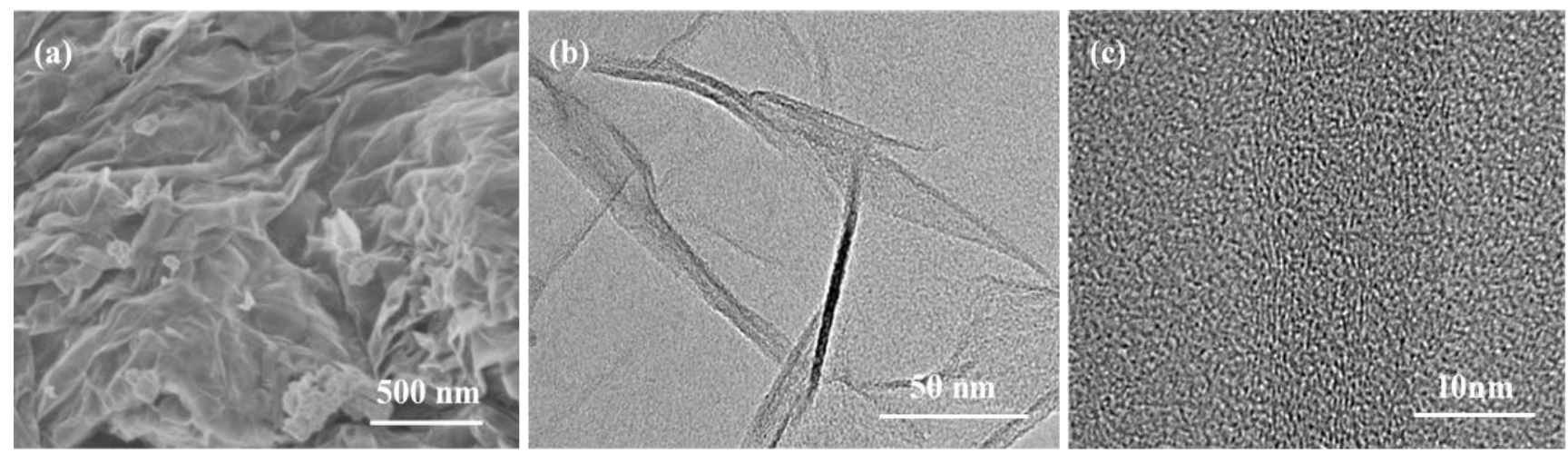

Fig. 2 SEM and TEM images of graphene: (a) SEM; (b) Low- and (c) higher-magnification TEM images of graphene. 

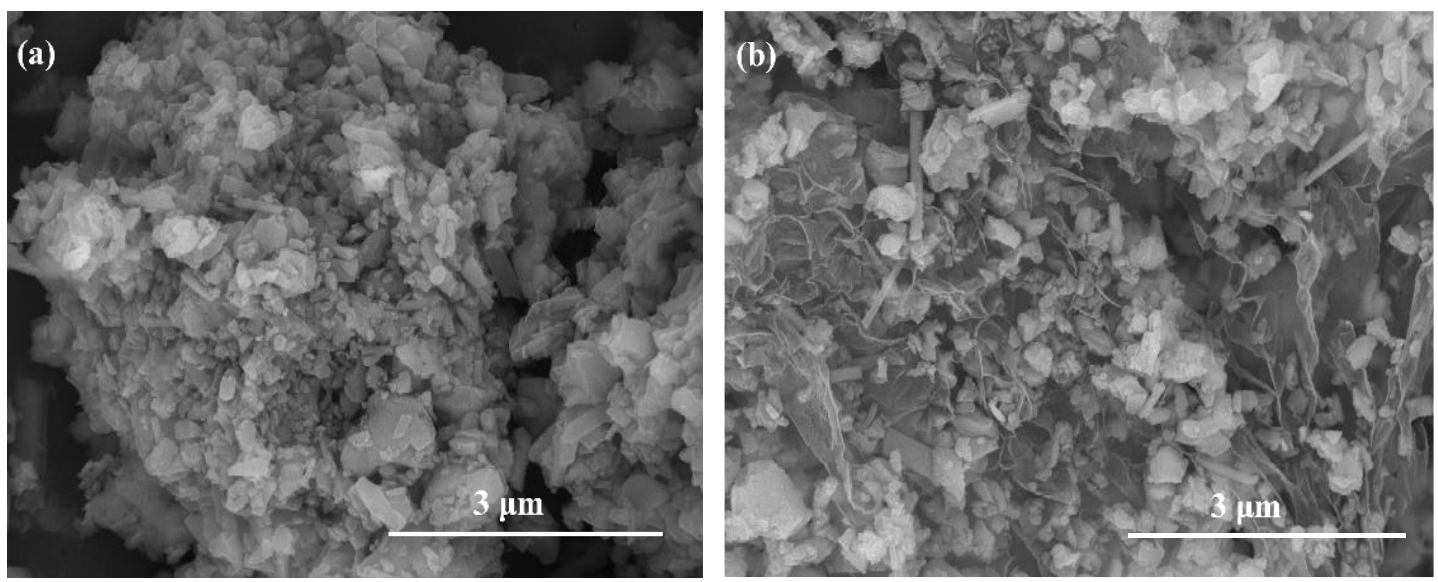

Fig. 3 SEM images of mixed powders: (a) SC without graphene; (b) SCG with graphene.

\subsection{Characterization}

Archimedes method was used to measure the densities $(\rho)$ and apparent porosities $(P)$ of samples. The flexural strength was determined via the three-point bending tests using electromechanical universal testing machine (CMT5150, China) on $3.0 \mathrm{~mm} \times 4.0 \mathrm{~mm} \times 36.0 \mathrm{~mm}$ test specimens with $30.0 \mathrm{~mm}$ support distance and $0.5 \mathrm{~mm} / \mathrm{min}$ crosshead speed. X-ray diffractometry (XRD, D8-ADVANCE, Bruker, Karlsruhe, Germany) analysis was used to identify the crystalline phases of raw materials and sintered samples in a $2 \theta$ range of $10^{\circ}$ to $80^{\circ}$ using $\mathrm{Cu} \mathrm{K} \alpha$ radiation. Scanning Electron Microscope (SEM, JSM-6510LV, JEOL, Tokyo, Japan) was used to observe the microstructure on the fracture surface of ceramics. In addition, the interfaces, particle morphology and composition information of the materials were further investigated by Transmission Electron Microscope (TEM, JEM-2100, JEOL, Tokyo, Japan).

\section{Results and discussion}

\subsection{Densification and mechanical property}

The density, porosity and flexural strength of samples were shown in Table 1. It was not difficult to see that both sample SC without admixture and SCG with graphene had high density after sintering, and the porosities of SC and SCG were less than 0.5 percent, which indicated that both samples were completely sintered. In the sintering process, the pores of samples move to the grain boundary gradually from the inside of the grain, and then discharge at the grain boundary, resulting in the densification of materials. ${ }^{[23]}$ As well known, it is usually accepted that the flexural strength of ceramics is inversely proportional to the porosity, and the higher the porosity, the lower the flexural strength. ${ }^{[23-25]}$ However, the flexural strength of material was significantly improved after adding graphene. As shown in Table 1, the porosity of sample SC and SCG was very similar, while the flexural strength of SCG (adding graphene), compared with SC, increase from 329.11 to 443.19 $\mathrm{MPa}$, which indicated that adding graphene was conducive to significantly improve the mechanical property of composite ceramics. The strengthening mechanism would be explained from the microstructures and compositions in the next chapter.
Table 1. Mechanical properties of $\mathrm{Si}_{3} \mathrm{~N}_{4} / \mathrm{SiC}$ composite ceramics.

\begin{tabular}{ccccc}
\hline Samples & Additives & $\begin{array}{c}\text { Density }(\rho) \\
\left(\mathrm{g} / \mathrm{cm}^{3}\right)\end{array}$ & $\begin{array}{c}\text { Porosity }(P) \\
(\%)\end{array}$ & $\begin{array}{c}\text { Flexural } \\
\text { strength } \\
(\mathrm{MPa})\end{array}$ \\
\hline SC & & 3.0485 & 0.4192 & 329.11 \\
SCG & graphene & 3.0012 & 0.4118 & 443.19 \\
\hline
\end{tabular}

\subsection{Phase composition and microstructure}

The phase compositions of the matrix were $\beta-\mathrm{Si}_{3} \mathrm{~N}_{4}$ and $\mathrm{SiC}$ as shown in Fig. 4 revealed by XRD analysis. Moreover, the $\alpha-\mathrm{Si}_{3} \mathrm{~N}_{4}$ crystal phase was not be observed indicating that the $\alpha-\beta$ phase transformation was complete for two samples at high temperature. It was not observed the characteristic peaks of graphene for sample SCG, although graphene was added in the experiment. Perhaps the $0.3 \%$ content of graphene was so small that it is not detected.

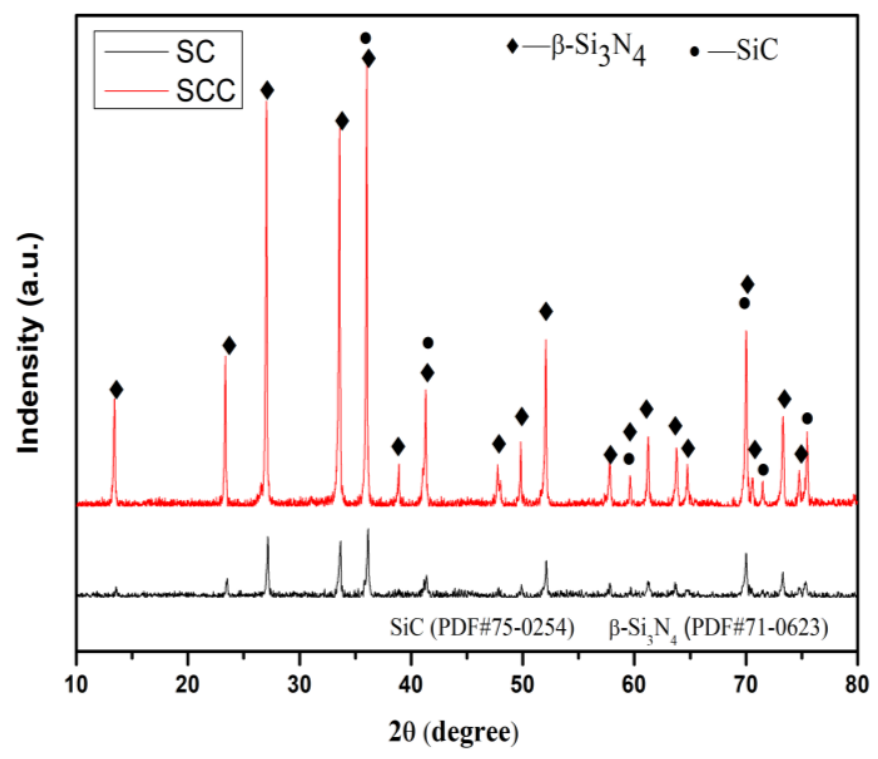

Fig. 4 XRD diagram of $\mathrm{Si}_{3} \mathrm{~N}_{4} / \mathrm{SiC}$ composites.

Fig. 5 shows the microstructure of the flexural fractured surfaces of the $\mathrm{Si}_{3} \mathrm{~N}_{4} / \mathrm{SiC}$ ceramics. The surfaces of samples SC and SCC were very dense, but the surface appearance showed very difference as shown in Fig.5 (a) and (c). At high- 

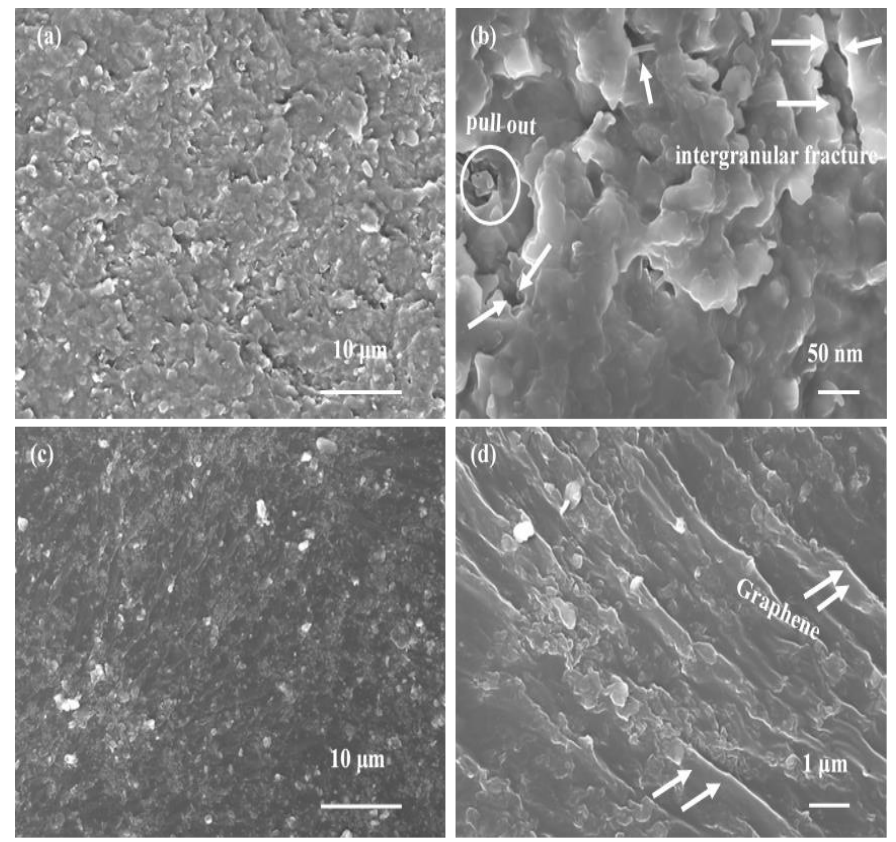

Fig. 5 SEM micrographs of the fractured surfaces of SC((a), (b)) and SCG $((\mathrm{c}),(\mathrm{d}))$.

resolution, there were many pores and bumpy like gully with disordered distribution on the surface of SC as shown in Fig. 5 (b). The morphology is mainly due to grain pullout and intergranular fracture of the rod-like $\beta-\mathrm{Si}_{3} \mathrm{~N}_{4}$ particles (represented by arrows) during the fracture process, which is also reflect the main fracture mechanisms. However, after adding graphene, the surface of SCG exhibited the layered structure with a directionality. From Fig. 5 (d), the fracture occurred mainly at the interface between graphene and ceramics matrix, the graphene platelets were embedded in the matrix. This phenomenon of graphene sheets being pulled out along the interface during fracture may be the main reason for the enhancement of SCG strength.

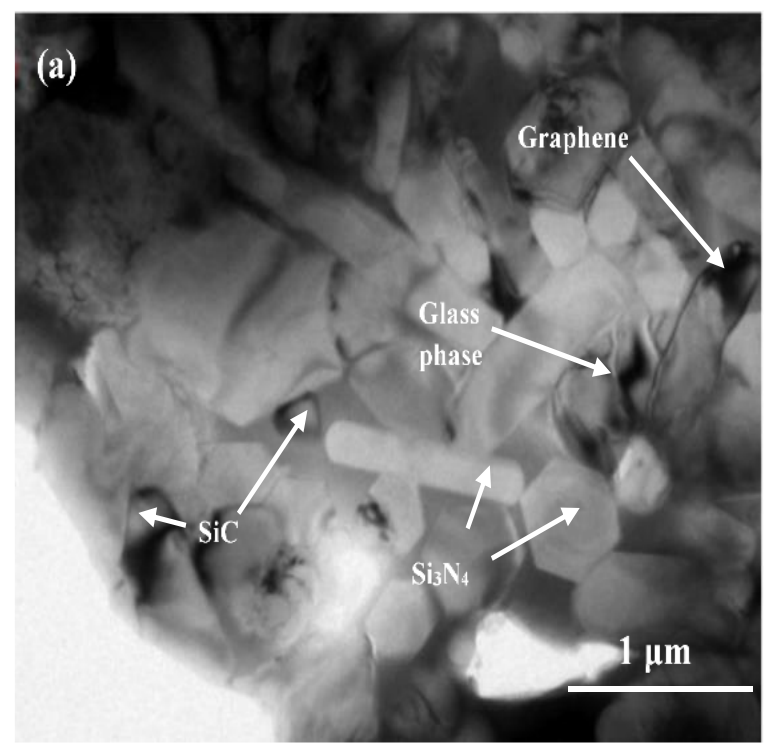

TEM was used on sample SCG to fully analyze the crystal phase composition and structure of samples. The structure of SCG was compact, and there are a large number of $\beta-\mathrm{Si}_{3} \mathrm{~N}_{4}$ grains (proved by the interfacial spacing value (Fig. 6 (b)) was $0.62 \mathrm{~nm}$ ) with high aspect ratio that contacted closely with glass phases. The structure of $\beta-\mathrm{Si}_{3} \mathrm{~N}_{4}$ is beneficial for the improve of strength due to its self-toughening effects such as pull-out and elastic bridging, while the size is too large can reduce the strength of ceramics. ${ }^{[2,15,26]}$ Fukasawa, et.al. studied the grain will be enhanced with the increase of sintering temperature. ${ }^{[27]}$ In this paper, $\mathrm{Si}_{3} \mathrm{~N}_{4} / \mathrm{SiC}$ ceramics were prepared with high sintering temperature, the $\mathrm{SiC}$ particles with irregular shape were observed in the grain boundary, which has an inhibitory effect on the secondary recrystallization of $\mathrm{Si}_{3} \mathrm{~N}_{4}$ grains to avoid the overgrowth of grains as reported. ${ }^{[20]}$ In Fig. 6 (a), it also appeared that graphene was embedded in the matrix, which was consistent with the described before in Fig. 5 (d). The role of graphene and $\mathrm{SiC}$ would be described detailly in the next chapter.

\subsection{Strengthening mechanisms}

Fig. 7 was the schematic graphics of phases compositions. For sample SC (Fig. 7(a)), the SiC grains were mainly located at the junction of $\mathrm{Si}_{3} \mathrm{~N}_{4}$ grain phases to pin grain boundaries. Studies show that the crack energy will be reduced when the crack tip touched the SiC hard particles, and then the crack stop propagating, or the crack deflection occurs. ${ }^{[18-21,28]}$ On the other hand, $\mathrm{SiC}$ could inhibit the overgrowth of $\beta-\mathrm{Si}_{3} \mathrm{~N}_{4}$ grains to reduce the appearance of large grains and get the $\beta-\mathrm{Si}_{3} \mathrm{~N}_{4}$ with high aspect ratio in the matrix. That made the microstructure more uniform and conduced to improve the strength of matrix by self-strengthen mechanism as mentioned before. As shown in Fig. 7(b), for sample SCG, the graphene sheets became in contact with multiple particles because of its high specific surface area and formed strong bonding

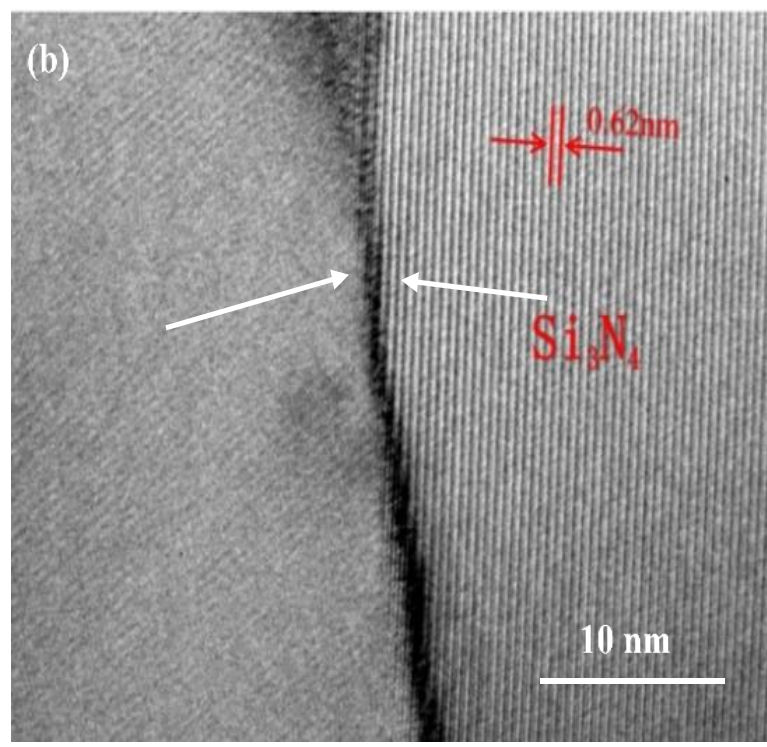

Fig. 6 TEM picture of the sample SCG: (a) TEM images; (b) HRTEM images. 


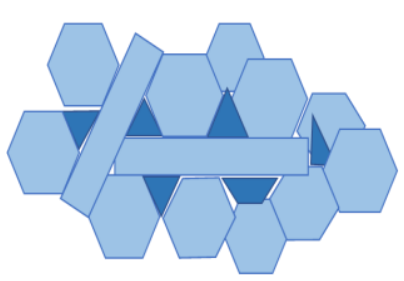

(a)

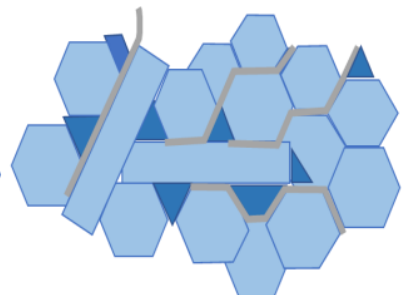

(b)

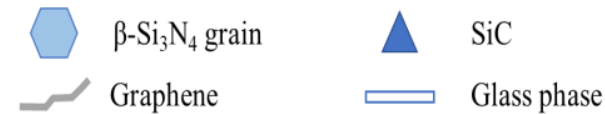

Fig. 7 Schematic graphics of phase composition in $\mathrm{Si}_{3} \mathrm{~N}_{4} / \mathrm{SiC}$ ceramics: (a) SC; (b) SCG.

interfaces with $\beta-\mathrm{Si}_{3} \mathrm{~N}_{4}$. It also could be found in SEM and TEM. When external force acts on the body, the crack will extend within the matrix and produce crack branching during this progress. Then, with the crack tips reach the interface between graphene and the matrix, the crack will deflect and extend along with the interface due to the excellent strength of graphene. Therefore, the material had to overcome stronger friction in this process to break up, and finally the graphene which perpendicular to the plane of the fracture surface was pulled out and tucked and wrapped around matrix grains, which explained why the surface showed the layer structure. Hence the main toughening mechanisms of SCG include crack branching and crack deflection caused by graphene besides those discussed in the SC above, which similar with that reported by Kvetkova and Walker et al..$^{[2,13,16]}$ This also explained why the flexural strength of SCG, compared with $\mathrm{SC}$, was significantly improved after adding graphene.

\section{Conclusions}

The influences of graphene on the mechanical and microstructure of $\mathrm{Si}_{3} \mathrm{~N}_{4} / \mathrm{SiC}$ composite ceramics were investigated. The results showed that the fracture strength of SCC whose porosity was similar to SC can be improved significantly after adding graphene with the value increase from 329.11 to $443.19 \mathrm{MPa}$. The main crystal phases of ceramics were $\beta-\mathrm{Si}_{3} \mathrm{~N}_{4}$ and $\mathrm{SiC}$, the graphene was not detected through XRD since the low content of graphene in the sample $\mathrm{SCC}$. The main toughening mechanisms of SC were grain pullout and intergranular fracture caused by $\beta-\mathrm{Si}_{3} \mathrm{~N}_{4}$, while after adding graphene, the main mechanism of SCC was crack deflection at graphene interface with the matrix. Besides, the $\mathrm{SiC}$ particles located in the grain boundary could avoid adverse effects on the strength due to the oversize $\beta-\mathrm{Si}_{3} \mathrm{~N}_{4}$ grains. The influences of graphene content on mechanical properties were not been discussed, which is our following work.

\section{Acknowledgements}

Authors appreciate the financial supported by the National Natural Science Foundation of China (Grant No. 51872118, 51701081), the Key Research and Development Program of
Shandong Province (Grant No. 2019GGX104077, 2019RKB01018), the Shandong Provincial Natural Science Foundation, (Grant No. ZR2018PEM008, ZR2019MEM055). The project supported by State Key Laboratory of Advanced Technology for Materials Synthesis and Processing (Wuhan University of Technology). This work was financially supported by National Natural Science Foundation of China (51632003), the Taishan Scholars Program, and the Case-byCase Project for Top Outstanding Talents of Jinan.

\section{Conflict of Interest}

There is no conflict of interest.

\section{Supporting Information}

Not applicable

\section{References}

[1] C.H. Lui, L. Liu, K. F. Mak, G.W. Flynn and T.F. Heinz, Nature, 2009, 462, 339-341, doi: 10.1038/nature08569.

[2] L.S. Walker, V.R. Marotto, M.A. Rafiee, N. Koratkar and E.L. Corral, ACS. Nano., 2011, 5, 3182-3190, doi: 10.1021/nn200319d.

[3] R. J. Young, I. A. Kinloch, L. Gong and K. S. Novoselov, Compos. Sci. Technol., 2012, 72, 1459-1476, doi: 10.1016/j.compscitech.2012.05.005.

[4] W.-M. Tian, -M. Li, B. Wang, X. Chen, J.-H. Liu and M. Yu, Int. J. Min. Met. Mater., 2016, 23, 723-729, doi: 10.1007/s12613016-1286-0.

[5] A. A. Balandin, S. Ghosh, W.Z. Bao, I. Calizo, D. Teweldebrhan, F. Miao and C. N. Lau, Nano. Lett., 2008, 8, 3902907, doi: $10.1021 / \mathrm{n} 10731872$.

[6] A. Kumar, K. Sharma and A.R. Dixit, J. Mater. Sci., 2019, 54, 5992-6026, doi: 10.1007/s10853-018-03244-3.

[7] U. Khan, P. May, A. O'Neill and J. N. Coleman, Carbon, 2010, 48, 4035-4041, doi: 10.1016/j.carbon.2010.07.008.

[8] J. L. Li, Y.C. Xiong, X.D. Wang, S.J. Yan, C. Yang, W.W. He, J.Z. Chen, S.Q. Wang, X.Y. Zhang and S.L. Dai, Mater. Sci. Eng. A, 2015, 626, 400-405, doi: 10.1016/j.msea.2014.12.102.

[9] R. Pérez-Bustamante, D. Bolaños-Morales, J. BonillaMartínez, I. Estrada-Guel and R. Martínez-Sánchez, J. Alloy. Compd., 2014, 615, 578-582, doi: 10.1016/j.jallcom.2014.01.225. [10] W. Kim, H.-S. Oh and I.-J. Shon, Int. J. Refract. Met. H., 2015, 48, 376-381, doi : 10.1016/j.ijrmhm.2014.10.011.

[11] Y.C. Fan, L.J. Wang, J.L. Li, J.Q. Li, S.K. Sun, F. Chen, L.D. Chen and W. Jiang, Carbon, 2010, 48, 1743-1749, doi: 10.1016/j.carbon.2010.01.017.

[12] C. Ramirez and M.I. Osendi, Ceram. Int., 2014, 40, $11187-$ 11192, doi: 10.1016/j.ceramint.2014.03.150.

[13] L. Kvetková, A. Duszová, P. Hvizdoš, J. Dusza, P. Kun and C. Balázsi, Scripta. Mater., 2012, 66, 793-796, doi: 10.1016/j.scriptamat.2012.02.009.

[14] C. Ramírez, S. M. Vega-Diaz, A. Morelos-Gómez, F. M. Figueiredo, M. Terrones, M.I. Osendi, M. Belmonte and P. Miranzo, Carbon, 2013, 57, 425-432, doi: 10.1016/j.carbon.2013.02.015. 
[15] E. Bódis, O. Tapasztó, Z. Károly, P. Fazekas, S. Klébert, A. M. Keszler, K. Balázsi and J. Szépvölgyi, Open. Chem., 2014, 13, 484-489, doi: 10.1515/chem-2015-0064.

[16] Z.-L. Li, J. Zhao, J.-L. Sun, F. Gong and X.-Y. Ni, Int. J. Min. Met. Mater., 2017, 24, 1403-1411, doi: 10.1007/s12613017-1533-z.

[17] Y.J. Huang and C.L. Wan, J. Adv. Ceram., 2020, 9, 271-291, doi: 10.1007/s40145-020-0376-7.

[18] J. Dusza, J. Kovalčík, P. Hvizdoš, P. Šajgalík, M. Hnatko and M. Reece, J. Eur. Ceram. Soc., 2004, 24, 3307-3315, doi: 10.1016/j.jeurceramsoc.2003.10.046.

[19] S. Lojanová, P. Tatarko, Z. Chlup, M. Hnatko, J. Dusza, Z. Leňčéš and P. Šajgalík, J. Eur. Ceram. Soc., 2010, 30, 1931-1944, doi: 10.1016/j.jeurceramsoc.2010.03.007.

[20] M. Kašiarová, B. Shollock, A. Boccaccini and J. Dusza, J. Am. Ceram. Soc., 2009, 92, 439-444, doi: 10.1111/j.15512916.2008.02848.x.

[21] D.-S. Cheong, K.-T. Hwang and C.-S. Kim, J. Am. Ceram. Soc., 1999, 82, 981-86, doi: 10.1111/j.11512916.1999.tb01863.x.

[22] B. A. Ahmed, T.Laoui and A.S. Hakeem, J. Adv. Ceram., 2020, 9, 606-616, doi: 10.1007/s40145-020-0400-y.

[23] G. Q. (Max) Lu, J. Mater. Process. Tech., 1996, 59, 297-302, doi: 10.1016/0924-0136(95)02171-X.

[24] J. Zhou, J.-P. Fan, G.-L. Sun, J.-Y. Zhang, X.-M. Liu, D.-H. Zhang and H.-J. Wang, J. Alloy. Compd., 2015, 632, 655-660, doi: 10.1016/j.jallcom.2015.01.305.

[25] Y. Xia, Y.-P. Zeng and D. Jiang, Cera. Int., 2011, 37, 37753779, doi: 10.1016/j.ceramint.2011.06.013.

[26] P. F. Becher, J. Korean Ceram. Soc., 2016, 53, 575-580, doi: 10.4191/kcers.2016.53.6.575.

[27] T. Fukasawa, Z. Y. Deng, M. Ando, T. Ohji and S. Kanzaki, J. Am. Ceram. Soc., 2002, 85, 2151-2155, doi: 10.1111/j.11512916.2002.tb00426.x.

[28] P. V. Kumar1, D. Jebakani1, C. Velmurugan and V. Senthil Kumar, Silicon, 2021, doi: 10.1007/s12633-020-00933-0.

\section{Author information}

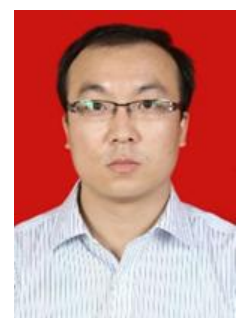

Qinggang Li, presently for University of Jinan Professor, Master Instructor, Member of the New Chemical Materials Committee of the Chemical Industry and Engineering Society of China, Member of SAMPE Beijing Chapter, working in Shandong Provincial Key Laboratory of Preparation and Measurement of Building Materials.

Publisher's Note Engineered Science Publisher remains neutral with regard to jurisdictional claims in published maps and institutional affiliations. 